\title{
Estimation of Substitution Possibilities Between Hydroelectricity and Classical Factor Inputs for Pakistan's Economy
}

\author{
Waqar Khalid ${ }^{1}$ and Hüseyin Özdeşer ${ }^{2}$
}

\begin{abstract}
Pakistan is a highly energy-dependent country and this dependence further increased primarily due to industrialization that has led to economic growth in recent years. Due to the economy's increased energy demands, domestic hydropower resources were switched to more expensive and greenhouse gas emitting imported petroleum products, thus leaving Pakistan exposed to oil price shocks and environmental degradation. In this article, we use the trans-log production specification to estimate the substitution elasticity of labour, capital, and energy in order to design government policies which will ensure higher economic growth, environmental sustainability, and energy security. To address the issue of multicollinearity, ridge regression is employed to estimate the coefficients of the model. Empirical findings report that labour-energy and capital-energy are substitutes over the period 1980-2017; hence, adopting competitive pricing policies and removal of petroleum subsidies and price ceilings would redirect industries towards an increased use of electricity and increase capital and labor intensiveness. The empirical findings further suggest convergence among input pairs in terms of relative technological progress, with labour recording the highest rate. These results suggest that petroleum would gradually lose its dominance in Pakistan's energy mix.
\end{abstract}

Keywords: Energy Substitution, Inter-Factor Substitution, Trans-Log Production Model, Ridge Regression, Pakistan

JEL Classification: D24, Q42, Q43, Q48, Q54, Q55

\section{Introduction}

Energy is a major contributor to economic growth in developing countries like Pakistan. The development of economic and technological activities requires a sufficient supply of energy. Developing countries like Pakistan have an increasing need for energy due to industrialization, population growth, urbanization, and economic development. Considering the oil crises and mini oilshocks that occurred during the 1990s and 2000s, the importance of energy has

\footnotetext{
${ }^{1} \mathrm{PhD}$ Scholar, Department of Economics, Near East University, Nicosia/TRNC, Cyprus

${ }^{2}$ Professor of Economics, Department of Economics, Near East University, Nicosia/TRNC, Cyprus

Corresponding author's Email: waqarkhalidicp@gmail.com
} 
further grown. Since energy has become a crucial input in the production process, it makes an economy more efficient and productive (Khalid et al., 2021).

Classical economists emphasized labour and capital as input factors in their growth models, but they did not recognize the importance of energy in production. In standard macroeconomic growth theories, primary energy inputs are not explicitly considered (Khalid and Jalil, 2019; Khalid et al., 2021). Industrialization, modernized agriculture, population growth, increased trade, improved transportation, and the frequent global oil shocks have made the energy factor a focus for economists and policymakers worldwide. Governments, societies, and many non-governmental organizations have been made more environmentally aware since the oil crises of the 1970s. Energy-saving technologies are an important tool for reducing $\mathrm{CO}_{2}$ emissions and the exhaustion of primary energy resources. Within the context of production functions, these energy-saving technologies can be characterized by a substitute of capital for energy (Koetse et al., 2008). Investments in new capital are not efficient, as they entail adjustment costs in the short-run (Ketteni et al., 2013).

The macroeconomic growth models largely explain the economic growth process in different countries (Aghion and Howitt, 2009); however, these models have ignored the use of energy as a factor input that could enable economic growth, although considerable attention is paid by economists to the impact of oil prices on the economic growth in the short-run (Hamilton, 2009). Many activities involved in production and consumption require energy as a crucial input. In fact, energy is one of the most important inputs in economic development. Energy is essential to modern economies as it drives productivity and industrial growth. Barney and Franzi (2002) state that energy drives at least half of industrial growth in a modern economy while accounting for less than one tenth of production costs. Therefore, ecological economists identify energy as a key player in economic growth (Stern, 2010). Thus, various articles have been written in the last two decades concerning the correlation between energy consumption and economic growth. According to Hou (2009), there was a bidirectional causal relationship between energy consumption and economic growth in China. According to Bayar and Ozel (2014), the association between energy consumption and economic growth in emerging economies was positively correlated and had a bidirectional causal relationship.

Since 2007, Pakistan's economy has endured a life-threatening energy crisis. This energy crisis is a result of a fuel mix transformation that began two decades ago when the power generation tended to rely more on imported furnace 
oil than hydropower. Over the years, the problem has evolved from chronic deficits in power supply to an excess of capacity installed but insufficient cash flow to operate it. Due to the resultant increased power generation costs, coupled with the high proportions of line losses, it has become necessary to increase tariffs, causing losses for power generation, transmission, and distribution companies. As a result, the energy sector is experiencing a phenomenon known as circular debt. Since 2008, the circular debt in Pakistan has increased from 1.6 percent of GDP (Rs 161 billion) to 5.2 percent of GDP (Rs 2,150 billion) by June 2020 (Government of Pakistan, 2021). This has negatively impacted the economy and employment generation capacity and has harmed social cohesion (Government of Pakistan, 2015). In Pakistan, the electricity deficit increased by 6,500 megawatts in 2017 (Kamran et al., 2020) as the demand for energy surpasses supply. Historically, the energy sector in Pakistan has been handicapped by a huge demand-supply gap, making the economy largely dependent on imported petroleum and incapable of producing enough electricity to meet domestic demands. As of April 2020, Pakistan's total electricity generation capacity was 35,972 MW, an increase of 7.5\% from 33,542 MW in April 2019 (Government of Pakistan, 2020). Pakistan's actual electricity generation capacity is lower than its installed electricity generation capacity due to several factors, including circular debt, transmission and distribution losses, high oil prices, electricity theft, indigenous energy resources, and poor planning (Shakeel et al., 2016). Pakistan's cost of doing business has significantly increased due to higher energy prices (Government of Pakistan, 2020). In order to meet the growing energy demand, hydropower has been replaced by expensive and $\mathrm{CO}_{2}$-emitting thermal energy, leaving the nation vulnerable to global oil crises and environmental degradation. This negatively impacted the economic growth of Pakistan. The government should concentrate on the utilization of hydropower to meet the energy needs by providing the lowest electricity price; thus, this shift would ensure economic growth and environmental sustainability (Khalid and Jalil, 2019).

The estimation of substitution possibilities of the energy factor has been the center of attention of numerous scholarly studies across the globe since 1973. Due to rising energy prices in the 1970s, developed economies began to address the issue of energy security (Berndt and Wood, 1975). However, because of the global warming and environmental degradation issues that have emerged in the era of globalization, this focus has further stimulated and the energy resources substitutability has become a classic topic from the standpoint of energy economists. In some cases, substitution elasticity between classical input factors 
has been considered as a policy tool for mitigating $\mathrm{CO}_{2}$ emissions (Wesseh and Lin, 2016). For instance, studies have been conducted to determine the influence of a carbon tax on $\mathrm{CO}_{2}$ emissions caused by the overutilization of thermal energy resources in major sectors of the country.

In different circumstances, the estimation of the substitution elasticity between two input factors is considered to be a key policy instrument for both single-industry and cross-industry analyses (Goldar et al., 2013). Therefore, understanding the parameter estimate of the substitution elasticity between twofactor inputs is necessary if an economist has a keen interest in adopting policy measures while considering the relative prices of the variable inputs (Battese et al., 1993). The possibility of substitution between two input factors mainly affects factor prices, demand for a particular factor, and the output level. Generally, if the estimate of the substitution elasticity between two inputs is found to be limited, then adjustment by a single firm/industry with the increasing input prices would be rather challenging. In such situations, industrialists are strongly encouraged to introduce substantial changes to the original modes of production in order to satisfy the cost-minimization condition (Mahmood, 1989). The estimated value of the substitution elasticity of two inputs is a policy instrument for achieving the sustained growth targets and the changes in factor-shares to the production in the long-term. In general, a higher estimated coefficient of the substitution elasticity between labour and capital may lead to a higher share of labour productivity without diminishing the GDP (Behrman, 1972). This means that if the estimated value of substitution elasticity between two factors is higher; one factor can be substituted for the other factor that has an abnormal increase in its market price during a production process. Similarly, the fast-growing factor can be substituted for the slow-growing factor; however, the higher-productive capacity factor can be substituted for the lower-productive capacity factor (Goldar et al., 2013). In Pakistan, the estimation of substitution possibilities between energy vs. nonenergy factors often plays a critical role in policymaking (Khalid et al., 2021).

One prime goal of the Vision 2025 plan is to provide energy to Pakistanis from $67 \%$ to $90 \%$ alongside a reduction in pollution to the desired level and the placement of Pakistan among the top 25 countries (Government of Pakistan, 2013). Though, the attainment of these targets has mainly been dependent on the possibilities of input factor substitutability, because the attainment of such goals is largely dependent on both the output level and the oil-shocks experienced in the global market. Consequently, these major issues have attracted the attention of research scholars from the whole world in order to analyze the energy vs. nonenergy factors substitutability; however, in Pakistan, this hot issue remains 
unresolved. In developing countries, there are relatively few research studies examining the inter-factor substitution between pairs of inputs, and this is also true for Pakistan's economy (Khalid and Jalil, 2019).

It has received less consideration from Pakistani researchers in regard to energy and the classical input factor substitution (Mahmud, 2000). Numerous studies have focused on Pakistan's large-scale manufacturing sector (Khan, 1989; Zahid et al., 1992; Khan and Rafiq, 1993; Khan et al., 2015). Several studies conducted in Pakistan found that labour, capital, and energy have limited substitution potential and demonstrated a decreasing return to scale in the manufacturing sector. According to the findings, there is little scope for skilled employment generation, and the sector experiences disembodied technological changes in the range of 3-5\% annually. In contrast, other studies indicated that the substitution elasticity between labour vs. capital was significantly higher in Pakistan's banking sector and there were increasing returns to scale. The existing literature on this topic is characterized by mixed empirical results. These studies primarily emphasis on the large-scale manufacturing industries of Pakistan; therefore, empirical estimates of technological progress and inter-factor substitution potentials in Pakistan's economy are limited (Khalid et al., 2021). Moreover, the majority of research studies available are outdated and no longer relevant.

The current study aims to investigate whether energy (i.e., hydroelectricity) and classical input factors (i.e., labour and capital) can be substituted to suggest policy measures to the government of Pakistan to attain high economic growth, secure energy supply, and environmental protection. Estimating the extent of substitution among labour, capital, and energy is extremely significant for various purposes, including output targets, energy prices, environmental sustainability, and fuel taxes (Wesseh and Lin, 2016). This study has used the log-linear trans-log production model to calculate output elasticities, substitution elasticities, and technological progress between pairs of labour, capital, and energy. Our empirical investigation of the output elasticities of a specific input factor will help us in identifying preferred input factors for ensuring economic growth. Similarly, empirical estimation of substitution elasticities helps to choose the most suitable factor to be substituted during production to ensure rapid growth, energy security, and environmental protection. Finally, the convergence of relative differences in the technological advancement of input factors will direct us in selecting the most favored factor that the government should concentrate on in the future. Accordingly, the authors are strongly convinced that the selected estimation procedures are adequate to achieve the 
main objectives of this study. Thus, this study contributes significantly to the subject of energy economics within the context of Pakistan's economy, since it outlines policy measures that can simultaneously resolve the conflicting problems listed above. According to the authors, the current study is the first attempt to examine Pakistan's economy in detail.

This paper is structured as follows: Section 2 reviews the empirical literature. Data sources and variables are outlined in Section 3. The methodology and estimation procedures are described in Section 4. The estimation findings are outlined in Section 5, and policy recommendations are discussed in Section 6.

\section{Literature Review}

There has been a wide range of scholarly studies conducted over the last two decades as to whether energy and the classical factors are substitutes. In the literature, the empirical findings have provided an apparent dichotomy: while most articles support the substitutability hypothesis, other articles support a complementary hypothesis of energy vs. non-energy factor inputs. Studies have examined the question of whether energy and capital (E-K) inputs are substitutes or complements (Apostolakis, 1990). Since the 1973 first oil crisis, at least fifty attempts have been made on energy-capital substitution (Thompson and Taylor, 1995). Energy-capital studies have concluded that they are substitutes; other research studies have demonstrated that they are complementary, and some studies have reported mixed findings. World scholars have attempted numerous research studies to find out the nature of the relationship between $\mathrm{K}$ and $\mathrm{E}$ by examining different sectors of the economy. For instance, Pindayck (1979) was the first to investigate the substitutability of energy and capital and concluded that E-K pairs were substituted for 10 countries. Furthermore, Humphrey and Moroney (1975), Griffin and Gregory (1976) and Halvorsen (1977) reported that E-K were substituted in their respective cross-sectional data analyses. Other studies that have also supported the energy and capital substitution hypothesis for the LDCs include Thompson and Taylor (1995), Christopoulos and Tsionas (2000), Hengyun et al (2008) and Onuonga et al (2011). Conversely, other studies on the energy vs. capital association carried out by Hudson and Jorgensen (1973), Berndt and Wood (1975) and Magnus (1979) found that E-K were complementary for their respective time-series data analyses. The studies of Khan (1989) and Krishnapillai and Thompson (2012) concluded that E-K has fewer substitution possibilities in the large-scale manufacturing sectors of Pakistan and the United States, respectively. Morriso (1993) found contradictory evidence regarding the strength of the association between E-K. Griffin and Gregory (1976) 
and Apostolakis (1990) declared that a time-series analysis reveals the short-run response to price changes; consequently, the estimate provides the complementary association between the factor inputs. In contrast, a cross-sectional analysis reveals the long-run responses to price changes; therefore, revealing a substitution relationship between $\mathrm{E}-\mathrm{K}$ inputs. Recent studies have found that $\mathrm{E}-\mathrm{K}$ is substitutable in production; hence, the long debate among scholars supports the E$\mathrm{K}$ substitutability hypothesis. However, the apparent dichotomy prevailing in energy economics literature is not yet resolved by scholars (Apostolakis, 1990).

Under the framework of the inter-factor modelling approach, Aziz (2007) calculated the magnitude of substitutability between non-energy and energy inputs and concluded that non-energy factors were perfect substitutes for energy factors. On the contrary, the results of the inter-fuel model showed that most fossil fuels can be substituted for one another. Magnus (1979) considered both energy and non-energy items (e.g., L, K, and other materials) for the Dutch enterprise sector considering time-series data from 1950-1976. The trans-log production function demonstrated that energy and labour were substitutes, energy and capital were complements, and labour and capital had fewer substitution possibilities. Furthermore, the coefficient of own-price elasticity of the input demand indicated that capital was more responsive to changes occurring in its own price; however, the labour input was less responsive. Chishti and Mahmood (1991) conducted a study on the Pakistan large-scale manufacturing industry. Considering time-series data spanning from 1960-1980, the authors estimated the substitution elasticity of labour, capital, and energy using the trans-log production model. E-L and K-L were found to be substitutes for each other, so the study supports a greater focus on skilled employment generation in the sector. Khan (1989) concluded that there were fewer substitution possibilities for the nested capital-energy and working capital-labor functions based on estimating the twolevel CES production function model. The findings reported that Pakistan's manufacturing sector is heavily dependent on capital-intensive production methods. In addition, the adjustment speed was found to be extremely slow, indicating that the internal structural rigidities caused the decreasing returns to scale. In contrast, Golder (2012) found higher substitution potentials between energy and non-energy factors in 22 Indian industries.

Using a trans-log production specification, Lin and Wesseh (2013) evaluated the substitution possibility between energy and non-energy pairs in China's chemical industry considering time-series data spanning from 1980-2009. Except for natural gas, all energy inputs were substitutes. However, the estimates of substitution elasticity revealed a greater potential for coal-gas and coal- 
electricity, and a lower potential for coal-oil. By utilizing the trans-log model, Smyth et al (2011) estimated the possibility of inter-factor substitution between labour, capital and energy in China's steel sector and demonstrated that labourenergy and capital-energy were close substitutes. The findings suggested that removing price ceilings on energy items would discourage energy consumption and increase capital-intensiveness in the sector. The substitution possibility between labour-energy was lower than between capital-energy; however, the substitution elasticity between labour-energy was high. Lin and Fei (2015) employed the trans-log production specification to investigate the agricultural sector of China by considering labour, capital, and energy. Based on data covering the period 1980-2012, it was found that labour output elasticity was the highest of all output elasticities. Moreover, the considered inputs can be substituted for one another, and E-K has the highest substitution elasticity. The results showed that there was no significant difference in the level of technological progress among the inputs, thus supporting the validity of convergence over time.

The study conducted by Lin and Liu (2017) investigated the possibility of inter-factor substitution between labour, capital, and energy in the heavy industry of China over the period 1980-2014, using a trans-log production specification. Output elasticity of the examined inputs was positive, while E-K was relatively high, revealing that China's heavy industries are both energy and capitalintensive. Furthermore, the findings showed all the inputs were substitutes, with a higher substitution potential between labour and capital. While the substitution elasticity between labour vs. energy is declining, the substitution elasticities of capital for labor and energy are increasing significantly. The study concluded that focusing more on capital input could boost China's energy security. Wang and Lin (2017) examined the substitution possibility of both inter-factors and inter-fuels in the Chinese iron and steel industry from 1985 to 2011. Study estimates indicated that E-K and E-L were substitutes, and that the substitution possibility in E-K was comparatively higher. Empirical findings revealed that oil, coal, and electricity were substitutes; however, the substitution potential in China is not as obvious due to pricing distortions. According to the study, market-driven reforms in regards to energy prices, increased energy substitution, and the encouragement of energy-saving technologies are the main way to guarantee energy security and lower $\mathrm{CO}_{2}$ emissions in China's steel and iron industry. A recent study carried out by Khalid and Jalil (2019) utilized the trans-log production specification to estimate the potential for inter-fuel substitution between oil, gas, coal, and hydroelectricity spanning from 1980-2013 in a study on Pakistan's energy sector. 
All pairs of energy inputs were reported as substitutes, and coal and natural gas were the only inputs with higher substitution potential. It was concluded that hydroelectricity could replace all energy inputs, thus decreasing Pakistan's dependence on thermal energy and increasing its renewable energy use.

\section{Data Description}

In this article, the specific macroeconomic variables included are total output, total employment, gross capital stock, and total primary energy consumption in Pakistan during the period 1980-2017. We convert all selected variables into natural logarithms which stabilizes the variance and enhances the statistical properties of the dataset. This logarithmic transformation also has the advantage that parameter coefficients can be interpreted as direct elasticities. In order to eliminate the impact of inflation, real GDP is measured in 2010 USD to reflect total output. Pakistan's total output has been taken from the World Development Indicators (WDI) (2018). Data on labour ${ }^{3}$ is taken from the State Bank of Pakistan publications (Handbook of Statistics on Pakistan Economy, 2010). All other variables are also taken from World Development Indicators (WDI) (2018). The data on Pakistan's capital stock in constant 2010 USD has been extracted from Penn World Tables and updated until 2017 following the same procedure. According to the Perpetual Inventory Method of calculation at constant prices $(2000=100)$, the capital stock variable is as follows:

$\mathrm{K}_{\mathrm{t}}=\mathrm{K}_{\mathrm{t}-1}(1-\delta)+\mathrm{I}_{\mathrm{t}}$

In Equation (1), $\mathrm{K}_{\mathrm{t}}$ denotes the capital stock in period $\mathrm{t}, \mathrm{K}_{\mathrm{t}-1}$ denotes the capital stock in period $\mathrm{t}-1, \mathrm{I}_{\mathrm{t}}$ denotes the gross investment in period $\mathrm{t}$ and $\delta_{\mathrm{t}}$ denotes the depreciation rate. The depreciation rate for hydropower generating units is 3.4 percent of actual costs ${ }^{4}$. Therefore, this study assumes that hydroelectric assets depreciate at a rate of $3.4 \%$ annually. The following expression was used to calculate the initial observation of the capital stock:

Capital Stock $\left(\mathrm{K}_{0}\right)=\frac{\text { Gross Investment }\left(\mathrm{I}_{\mathrm{t}}\right)}{\text { Average growth rate of GDP }(\mathrm{g})+\text { Depreciation Allowance }(\delta)}$

In Equation (2), $K_{0}$ denotes the capital stock in period $t(1980), I_{t}$ denotes the gross investment in period $t, \mathrm{~g}$ denotes the average GDP growth rate in period $\mathrm{t}, \delta$ denotes the depreciation rate, and $\mathrm{t}$ denotes the index series. As a proxy for hydroelectricity consumption, hydropower generation is used in our study. This series is measured using the Quadrillion BTU and data on hydropower

\footnotetext{
${ }^{3}$ The variable labour has been proxy by the total employment of Pakistan.

${ }^{4}$ Finance Act (2018)
} 
consumption is considered from the Energy Information Administration (EIA) (2018). Figure 1 displays the plot of variables which shows a similar upward trend and variability over the sampling period; thus, indicating that the dataset is trend stationary.
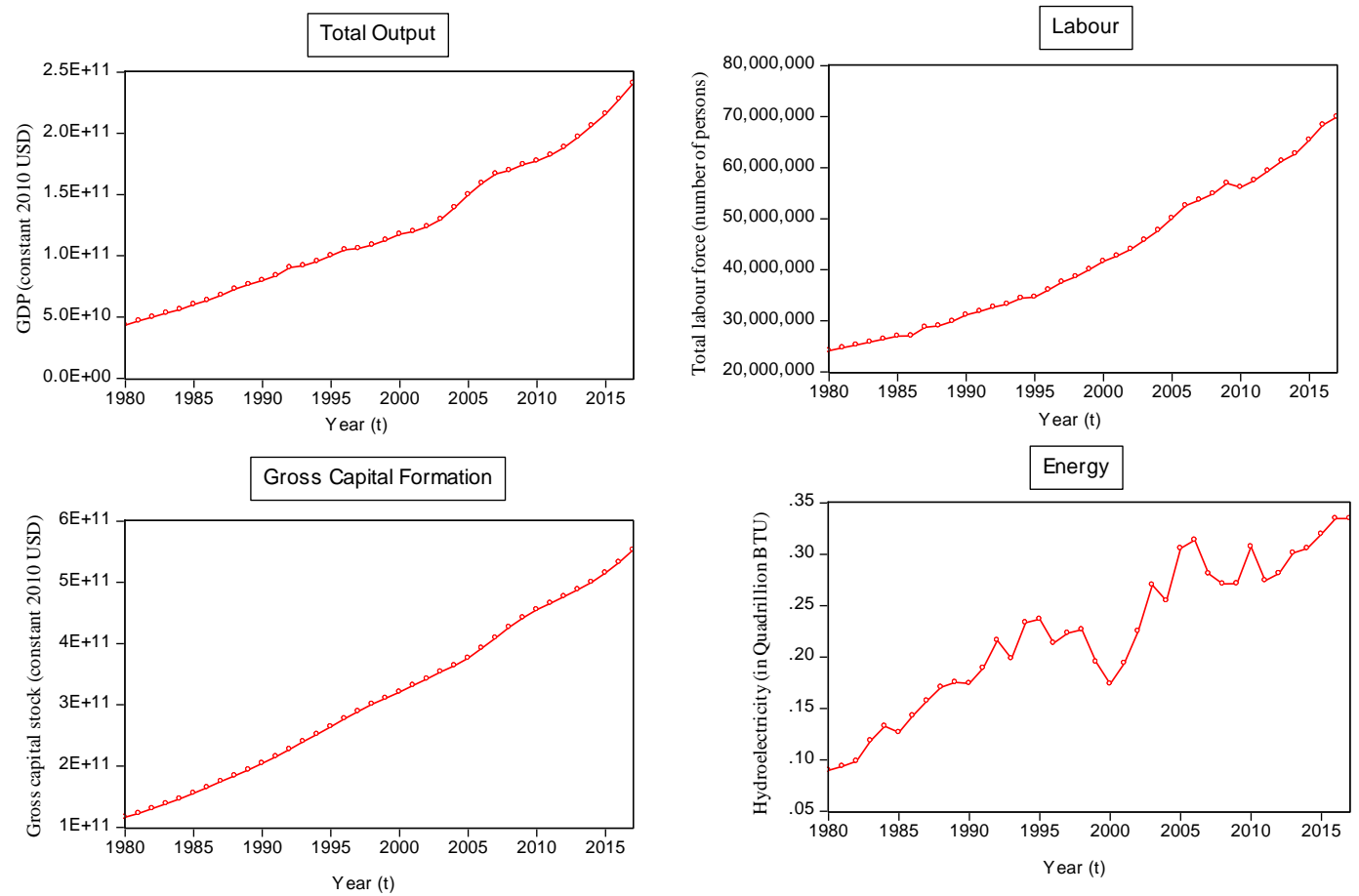

Figure-1: Plot of Variables over the sampling period, 1980-2017.

\section{Methodology and Estimation Procedure}

In order to examine the possibility of inter-factor substitution among labour, capital, and energy in Pakistan's economy, we dealt with the production function literature. It is crucial to choose the most appropriate production function for estimation purposes because its empirical analysis has several applications in the economy. Originally, labour and capital inputs were considered in production functions to estimate the degree of substitution employing the standard CobbDouglas (C-D) production specification (Khilji, 1982; Naqvi et al., 1983, 1992). Scholars criticized the standard C-D production specification for its rigidity and constant returns to scale assumptions. In the presence of more than two inputs, the standard C-D production function becomes ineffective since it assumes the unitelasticity between the inputs (Khan, 1989). In 1973, energy inputs became prominent among economists and therefore were included in econometric 
analyses to explore the elasticities between energy vs. non-energy inputs in different sectors. Numerous studies have investigated the substitution prospect between energy and non-energy factors (Magnus 1979; Mahmud 2000; Adeyemo et al., 2007; Koetse et al., 2008; Khalid and Jalil 2019). The empirical literature guides us that either the constant elasticity of substitution (CES) or the variable elasticity of substitution (VES) production functions may be employed to test the E-K substitutability hypothesis (Koetse et al., 2008). VES has the advantage that it does not restrict the estimates of substitution coefficients. Pavelescu (2011) stated that the flexible production function permits to avoid the imposition of assumption of perfect competition and perfect substitution among inputs. The quadratic term permits a nonlinear relationship between the output and inputs. Therefore, researchers find trans-log production functions attractive for estimation purposes. We also employed the translog production specification since we could not find input prices for the data under examination (Lin and Ahmad, 2016).

Microeconomics suggests that the widely accepted flexible production specification is the log-linear trans-log production model developed by Christensen et al (1973). For estimating the inter-factor substitution, this production model has been used in many empirical studies because of its superiority over the CES production framework. The coefficient estimates of this production function are simple and easy to calculate when compared to other production functions. This production framework also has the advantage that it does not impose any restrictions on the parameters of the model concerning the producer's behavior and his production strategy. The studies that have utilized this production function for testing the substitutability hypothesis between energy vs. non-energy inputs include Hengyun et al. (2008), Koetse et al (2008), Smyth et al (2012), Lin and Wesseh (2013), Xie and Hawkes (2015), Lin and Atsagl (2017), Lin and Liu (2017), Khalid and Jalil (2019), and Khalid et al (2021). Using the trans-log production model, the current study has also attempted to compute the inter-factor substitution for Pakistan's economy. In Equation 3, this production can be expressed as follows:

$Y_{t}=f\left(X_{1 t}, X_{2 t}, X_{3 t}, \ldots, X_{n t}\right)$

The general specification of the trans-log production framework is given by Equation (4):

$Y_{t}=\beta_{0}+\prod_{i=1}^{n} X_{i t}{ }^{\beta_{i}} \prod_{i=1}^{n} X_{i t}{ }^{1 / 2\left(\sum_{j=1}^{n} \beta_{i j} \ln X_{j t}\right)}$

Taking the natural logarithm of Equation (4), we can obtain the algebraic formulation of the trans-log production specification as shown in Equation 5: 


$$
\ln \left(Y_{t}\right)=\ln \left(\beta_{0}\right)+\sum_{i=1}^{n} \beta_{i} \ln \left(X_{i t}\right)+1 / 2 \sum_{i=1}^{n} \sum_{j=1}^{n} \beta_{i j} \ln \left(X_{i t}\right) \ln \left(X_{j t}\right)
$$

In Equation (5), $Y_{t}$ represents the real GDP of Pakistan in period $t, \beta_{0}$ represents the efficiency parameter, $X_{i t}$ and $X_{j t}$ denote the factor inputs $i$ and $j$; whereas $\beta_{i}$ and $\beta_{i j}$ denote the parameters to be estimated. According to earlier studies, trans-log production is CRS and Hicks-neutral. The dual of this twicedifferentiable production function is a twice-differentiable production model, which can be specified as follows:

$\ln Y_{t}=\beta_{0}+\beta_{L} \ln L_{t}+\beta_{K} \ln K_{t}+\beta_{E} \ln E_{t}+\beta_{L K} \ln L_{t} \ln K_{t}+\beta_{L E} \ln L_{t} \ln E_{t}+$

$\beta_{K E} \ln K_{t} \ln E_{t}+\beta_{L L}\left(\ln L_{t}\right)^{2}+\beta_{K K}\left(\ln K_{t}\right)^{2}+\beta_{E E}\left(\ln E_{t}\right)^{2}+\varepsilon_{t}$

In Equation (6), $Y_{t}$ represents Pakistan's total output for the period $t$, whereas $L_{t}, K_{t}$ and $E_{t}$ represent the factor inputs of labour, capital, and energy; respectively, $\beta_{0}$ is the constant, $\beta_{i}$ represents the coefficients, $t$ is the sampling period, and $\varepsilon_{t}$ is the disturbance term. The Young theorem for partial derivatives applied to the model indicates that parameters are symmetric $\left(\beta_{i j}=\beta_{j i} \forall i, j\right)$. When Equation (6) is differentiated with respect to labour, the output elasticity of labour can be determined as follows:

$\vartheta L=\frac{d Y / Y}{d L / L}=\frac{d \ln Y_{t}}{d \ln L_{t}}=\beta_{L}+\beta_{L K} \ln K_{t}+\beta_{L E} \ln E_{t}+2 \beta_{L L} \ln L_{t}>0$

The output elasticity of capital can be determined as follows:

$\vartheta K=\frac{d Y / Y}{d K / K}=\frac{d \ln Y_{t}}{d \ln K_{t}}=\beta_{K}+\beta_{L K} \ln L_{t}+\beta_{K E} \ln E_{t}+2 \beta_{K K} \ln K_{t}>0$

The output elasticity of energy can be determined as follows:

$\vartheta E=\frac{d Y / Y}{d E / E}=\frac{d \ln Y_{t}}{d \ln E_{t}}=\beta_{E}+\beta_{L E} \ln L_{t}+\beta_{K E} \ln K_{t}+2 \beta_{E E} \ln E_{t}>0$

The primary objective of the current study is to determine the substitution elasticity for labour, capital and energy in Pakistan; therefore, it is essential to estimate the substitution elasticity. The substitution elasticity of labour and capital is derived as follows:

$\sigma_{L K}=\frac{d(L / K)}{L / K} *\left\lceil\frac{d\left({ }^{M P_{K} / M P_{L}}\right)}{M P_{K} / M P_{L}}\right]^{-1}=\frac{d(L / K)}{d\left({ }^{M P_{K} / M P_{L}}\right)} * \frac{\left({ }^{M P_{K} / M P_{L}}\right)}{L / K}$

As we know that, 
$\frac{M P_{K}}{M P_{L}}=\frac{\partial Y / \partial K}{\partial Y / \partial L}=\frac{\eta_{K}}{\eta_{L}} * \frac{L}{K}$

In Equation (11), $M P_{K}$ and $M P_{L}$ show the marginal products of capital and labour, respectively. Substituting Equation (11) into Equation (10), Equation 12 can be expressed as follows:

$\sigma_{L K}=\frac{d(L / K)}{d\left({ }^{M P_{K} / M P_{L}}\right)} * \frac{\eta_{K}}{\eta_{L}}=\frac{\eta_{K}}{\eta_{L}} *\left[\frac{d\left(M P_{K} / M P_{L}\right)}{(L / K)}\right]^{-1}=\frac{\eta_{K}}{\eta_{L}} *\left[\frac{d\left(\frac{\eta_{K}}{\eta_{L}} * / K_{K}\right)}{d(L / K)}\right]^{-1}$

Due to the fact,

$\frac{d\left(\frac{\eta_{K}}{\eta_{L}} * / K\right)}{d(L / K)}=\left[\frac{\eta_{K}}{\eta_{L}}\right]+[L / K] *\left[\frac{d\left(\eta_{K} / \eta_{L}\right)}{d(L / K)}\right]$

Also,

$d\left[\frac{\eta_{K}}{\eta_{L}}\right]=-\left[\frac{\eta_{K}}{\left(\eta_{L}\right)^{2}}\right] * d \eta_{L}+\left[\frac{1}{\eta_{L}}\right] * d \eta_{K}$

And,

$d\left(\frac{L}{K}\right)=-\left[\frac{L}{K^{2}}\right] * d K+\left[\frac{I}{K}\right] * d L$

Combining Equation (14) and Equation (15), the resulting equation is as follows:

$\frac{d\left[\eta_{K} / \eta_{L}\right]}{d[L / K]}=\frac{-\left[\frac{\eta_{K}}{\left(\eta_{L}\right)^{2}}\right] * d \eta_{L}+\left[\frac{1}{\eta_{L}}\right] * d \eta_{K}}{-\left[\frac{L}{K^{2}}\right] * d K+\left[\frac{I}{K}\right] * d L}$

By dividing each term of the numerator and denominator with $(d K)$, we yield the following expression:

$\frac{d\left[\eta_{K} / \eta_{L}\right]}{d\left[\left[^{L} / K\right]\right.}=\frac{-\left[\frac{\eta_{K}}{\left(\eta_{L}\right)^{2}}\right] * d \eta_{L}+\left[\frac{1}{\eta_{L}}\right] * d \eta_{K}}{-\left[\frac{L}{K^{2}}\right] * d K+\left[\frac{I}{K}\right] * d L}=\frac{-\left[\frac{\eta_{K}}{\left(\eta_{L}\right)^{2}}\right] * \frac{d \eta_{L}}{d K}+\left[\frac{1}{\eta_{L}}\right] * \frac{d \eta_{K}}{d K}}{-\left[\frac{L}{K^{2}}\right] * \frac{d K}{d K}+\left[\frac{I}{K}\right] * \frac{d L}{d K}}=\frac{-\left[\frac{\eta_{K}}{\left(\eta_{L}\right)^{2}}\right] * \frac{d \eta_{L}}{d K}+\frac{1 d \eta_{K}}{\eta_{L} d K}}{-\left[\frac{L}{K^{2}}\right]+\frac{1 d L}{K d K}}$

The substitution elasticity between labour vs. capital can be calculated by substituting Equation (17) into Equation (12):

$\delta_{L K}=\left[1+\left[-\beta_{L K}+\left\{\frac{\eta_{L}}{\eta_{K}}\right\} * \beta_{K K}\right]\left(-\eta_{L}+\eta_{K}\right)^{-1}\right]^{-1}$ 
The substitution elasticity between labour vs. energy can be calculated as follows:

$$
\delta_{L E}=\left[1+\left[-\beta_{L E}+\left\{\frac{\eta_{L}}{\eta_{E}}\right\} * \beta_{E E}\right]\left(-\eta_{L}+\eta_{E}\right)^{-1}\right]^{-1}
$$

The substitution elasticity between capital vs. energy can be calculated as follows:

$$
\delta_{K E}=\left[1+\left[-\beta_{K E}+\left\{\frac{\eta_{K}}{\eta_{E}}\right\} * \beta_{E E}\right]\left(-\eta_{K}+\eta_{E}\right)^{-1}\right]^{-1}
$$

An estimated value of positive substitution elasticity between two factors will indicate the inputs are substitutes ${ }^{5}$; however, a negative substitution elasticity will reveal complementarity between the inputs; the two factors are viewed as complements ${ }^{6}$.

Correlation analysis among the regressors is the first step in the estimation procedure. It measures whether or not there is multicollinearity among the explanatory variables. By using Pearson's correlation test, it can be established that there is significant multicollinearity among the variables. Findings of the correlation matrix suggest that we cannot use Ordinary Least Squares (OLS) to estimate the coefficients of the trans-log production framework. Significant multicollinearity leads to spurious regression results, inflated S.Es, insignificant p-values, and less predictive power. In order to obtain accurate coefficients, the OLS regression will be slightly modified by introducing a bias to the regression coefficients; therefore, S.Es will be reduced. For this purpose, the ridge regression developed by Hoerl and Kennard (1970) is applied, which is the most appropriate estimation technique in dealing with multiple regression models with high multicollinearity. Several scholars have used the ridge regression technique in their respective studies (Smyth et al., 2011; Lin and Wesseh, 2013; Lin and Fei, 2015; Khalid and Jalil, 2019; Khalid et al., 2021). By adding a bias to the diagonal values of the correlation matrix, this regression technique increases the efficiency of the coefficients. Using ridge estimators, which are a variety of shrinkage estimators, this estimation technique creates new estimates that are closer to the true population parameters. In cases of multicollinearity, this shrinkage estimator can be particularly useful for improving OLS estimates.

$$
\begin{aligned}
& { }^{5} \delta_{i j}>0 \\
& { }^{6} \delta_{i j}<0
\end{aligned}
$$


Using the OLS method, the coefficients are estimated using the following expression:

$$
\hat{\beta}_{O L S}=\left(X^{\prime} X\right)^{-1} X^{\prime} Y
$$

If the data have significant multicollinearity, the cross-product matrix $\left(X^{\prime} X\right)$ is nearly a singular matrix; therefore, the variance of the OLS estimators has large values, while the possibility of non-rejection of the null hypothesis increases. Since the explanatory variables of the model are now standardized $\left(X^{\prime} X=R\right)$; therefore, the calculated estimates become unbiased.

$$
E(\hat{\beta})=\beta
$$

Equation (23) can be used to formulate the variance-covariance matrix of the coefficients:

$\operatorname{Var}(\hat{\beta})=\delta^{2}\left(X^{\prime} X\right)^{-1}=\delta^{2} R^{-1}$

For the empirical analysis, we use the standardized variables as follows:

$\operatorname{Var}\left(\hat{\beta}_{j}\right)=r^{j j}=\frac{1}{1-R_{j}^{2}} \quad j=1,2,3, \ldots, n$.

In Equation (24), $R_{j}^{2}$ denotes the R-squared value calculated from regression $X_{j}$ on other explanatory variables. The variance in this case is called the Variance Inflation Factor (VIF). As the $\mathrm{R}^{2}$ value approaches unity, the VIF value increases. The VIF value indicates multicollinearity when the $\mathrm{R}^{2}$ calculated value is equal to or higher than 0.90 . Ridge regression adds a ridge parameter $(\mathrm{K})$ to the $X^{\prime} X$ matrix, therefore resulting in a new matrix. The following expression can be used to calculate ridge coefficients:

$\hat{\beta}(K)_{P * 1}=\left(X^{\prime} X+K I_{P * p}\right)^{-1} X^{\prime} Y$

In Equation (25), $I_{P * p}$ is the identity matrix with order $p$ and $K$ is the ridge parameter that is positive but less than unit. The ridge coefficients converge to the OLS coefficients if $\mathrm{K}$ is equal to 0 . As the biasing parameter increases, the value of the standardized coefficients changes, often large at first. It appears that the coefficients narrow down at some interval before drifting slowly towards zero. If $K$ increases, the $R^{2}$ decreases, since $R^{2}$ is a decreasing function of $K$. The sampling variance of $\hat{\beta}_{(K)}$ decreases considerably with the increase in $K$, but the bias of the estimate $\hat{\beta}_{(K)}$ increases. The amount of bias in the ridge parameter can be stated as follows: 


$$
E(\hat{\beta}-\beta)=\left[\left(X^{\prime} X+K I_{P * p}\right)^{-1} X^{\prime} X-I\right] \beta
$$

The covariance-matrix can be expressed as follows:

$\operatorname{Var}(\hat{\beta})=\left(X^{\prime} X+K I\right)^{-1} X^{\prime} X\left(X^{\prime} X+K I\right)^{-1}$

Equation (28) gives the VIF for the ridge regression coefficients:

$$
V I F=(n-1) *\left(X^{\prime} X+K I\right)^{-1} X^{\prime} X\left(X^{\prime} X+K I\right)^{-1}
$$

In the application of ridge regression, the biasing constant needs to be selected appropriately among $\mathrm{K}$ trial values. In order to determine the appropriate value of K, Hoerl and Kennard (1970) proposed tracing an ideal graph, which they called the ridge trace. Using this graphical method, the standardized coefficients can be plotted against the biasing constant. In this graphical plot, the optimal value is considered at the point where the ridge coefficients $\left(\hat{\beta}_{\text {ridge }}\right)$ appear to stabilize and the wrong sign of ridge coefficients becomes correct. The ridge trace suggests selecting the lowest value of $K$ at the point where the standardized coefficients remain stable, thus ensuring the most accurate model.

\section{Empirical Results}

The Pearson correlation test shows that all the pairwise correlations are highly significant, hence, using the Evans (1996) correlation benchmark, it can be demonstrated that the dataset is highly multicollinear. According to Table 1, all of the pairwise correlation coefficients are between 0.80 and 1.0.

Table 1: Correlation Analysis

\begin{tabular}{ccccc}
\hline Variable & $\ln \mathbf{l n}$ & $\ln$ & $\operatorname{lnK}$ & $\operatorname{lnE}$ \\
\hline $\ln \mathrm{Y}$ & 1.0000 & 0.9902 & 0.9964 & 0.9514 \\
$\operatorname{lnL}$ & 0.9902 & 1.0000 & 0.9843 & 0.9126 \\
$\operatorname{lnK}$ & 0.9964 & 0.9843 & 1.0000 & 0.9485 \\
$\operatorname{lnE}$ & 0.9514 & 0.9126 & 0.9485 & 1.0000 \\
\hline
\end{tabular}

Source: Data processed by the author

Moreover, the $V I F_{i}$ for each explanatory variable is very high (i.e., >10). Findings confirm that the data exhibit severe multicollinearity. Tolerance statistic $\left(T O L_{i}=1-R_{x}{ }^{2}\right.$ ) is also used to check for multicollinearity, as it is closely related to $V I F_{i}$. Econometrics states that the closer $T O L_{i}$ is to zero, the greater the possibility of multicollinearity of an independent variable with the rest of the independent variables of the auxiliary model. The findings of $V I F_{i}$ and $T O L_{i}$ are given in Table 2. 

for Pakistan's Economy

Table 2: R-squared values from the Auxiliary Regressions

\begin{tabular}{|c|c|c|c|}
\hline Independent Variable & VIF7 & $R^{2}$ Value & TOL \\
\hline $\operatorname{lnL}$ & 5244937.1033 & 1.0000 & 0.0000 \\
\hline $\ln K$ & 9989483.6005 & 1.0000 & 0.0000 \\
\hline $\ln E$ & 1411560.7995 & 1.0000 & 0.0000 \\
\hline $\operatorname{lnL} * \ln K$ & 204307215.1538 & 1.0000 & 0.0000 \\
\hline $\operatorname{lnL} * \ln E$ & 2277547.2560 & 1.0000 & 0.0000 \\
\hline $\operatorname{lnK} * \ln E$ & 3813880.1759 & 1.0000 & 0.0000 \\
\hline$(\operatorname{lnL})^{2}$ & 37182329.3042 & 1.0000 & 0.0000 \\
\hline$(\ln K)^{2}$ & 80060780.5097 & 1.0000 & 0.0000 \\
\hline$(\ln E)^{2}$ & 8129.0435 & 0.9999 & 0.0001 \\
\hline
\end{tabular}

Source: Data processed by the author

Multicollinearity compels us to change the estimation technique from OLS to ridge regression. Using the ridge trace of the standardized coefficients shown in Figure 2, we chose 0.01 as the ridge parameter. Choosing $K=0.01$ as the optimal value is justified by the fact that all the standardized coefficients are fairly stable at this point. The translog production framework is used to compute output elasticities and substitution elasticities for the variables considered with a biasing constant of 0.01 .

Because the ridge regression aims to remove severe multicollinearity from the data, it is appropriate to determine at what level the problem has been resolved. The current study uses a plot of the VIF to illustrate the impact of the ridge parameter on the VIFs for this purpose. The rule-of-thumb of multicollinearity is that the VIF has to be less than 10 if it won't be a serious issue in the data (Gujarati, 2004; Asteriou and Hall, 2011). Figure 3 shows that the VIFs are lower than 10 when the optimum ridge parameter is set to 0.01 .

\footnotetext{
${ }^{7}$ Since all VIFs are significantly greater than 10 , multicollinearity is evident in the data.
} 


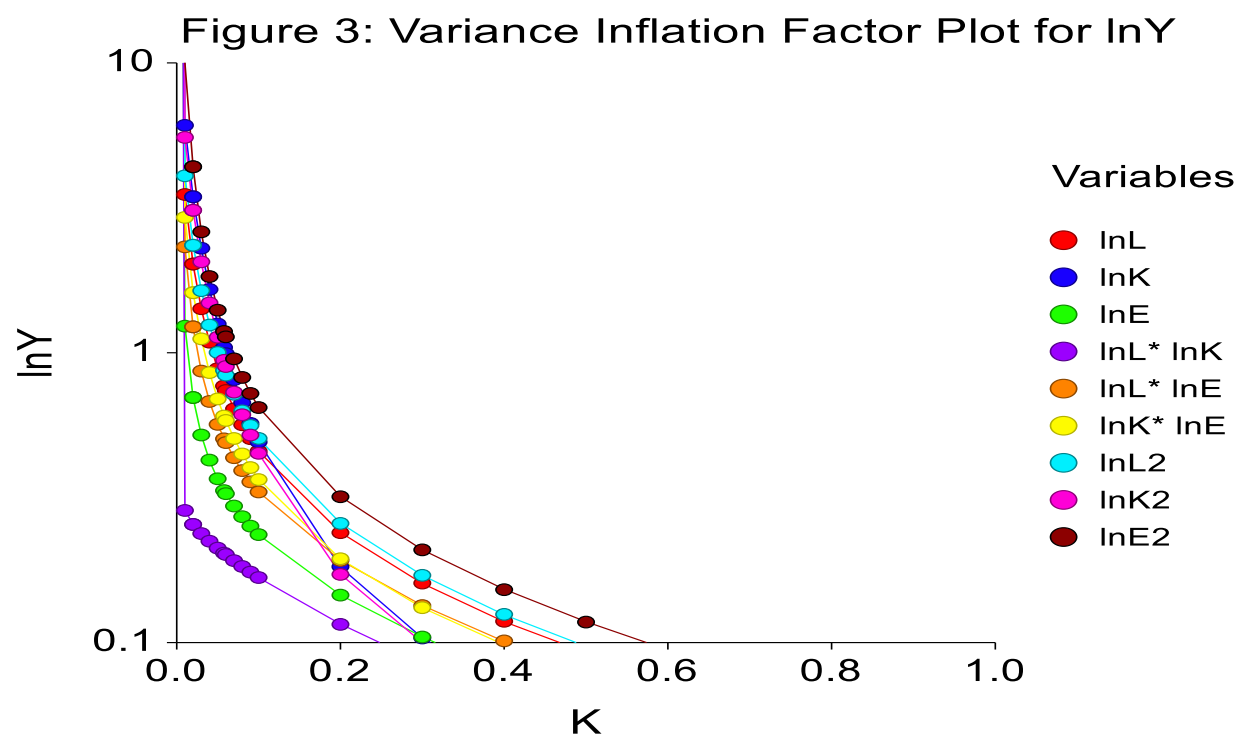

Source: Results extracted from the NCSS 12

VIF calculated values are reported in Table 3, which is visually plotted on the graphical plot of the VIF. Table 3 demonstrates that all VIFs are significantly less than 10 when $K=0.01$, suggesting that multicollinearity has no further significance in the data.

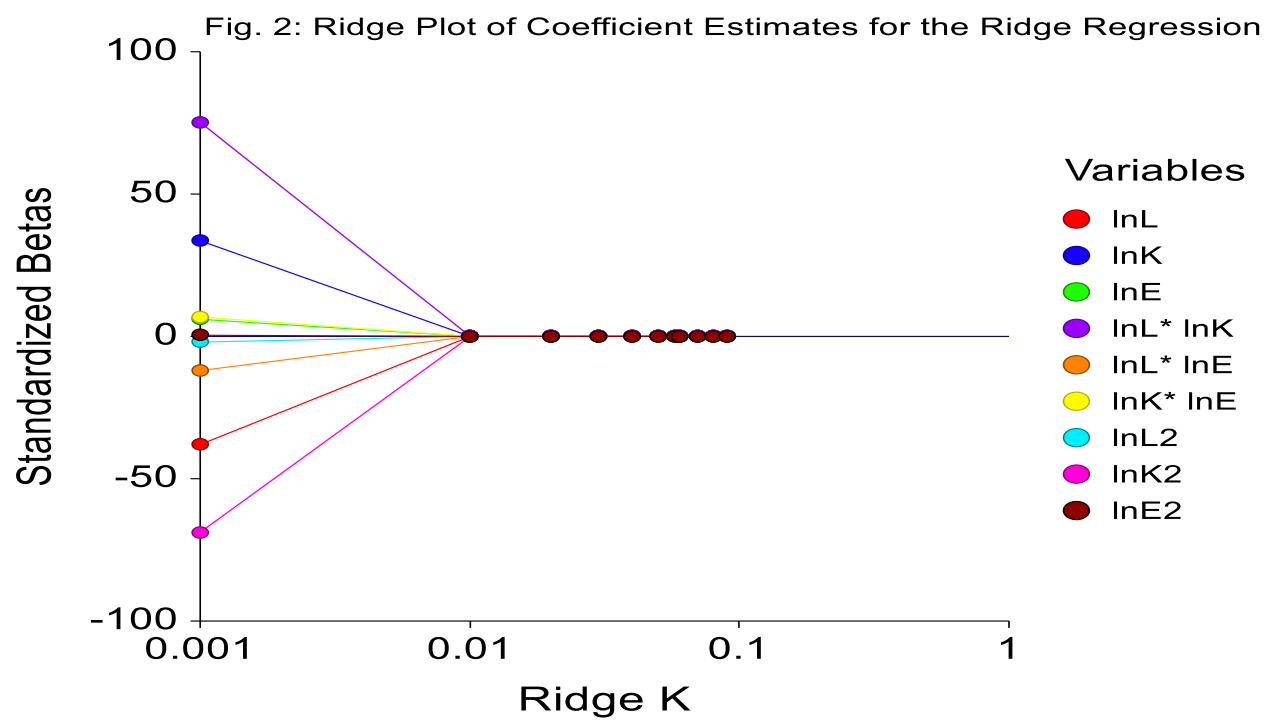

Source: Results extracted from NCSS 12 
Table 3: Coefficient's analysis of VIFs

\begin{tabular}{|c|c|c|c|c|c|c|c|c|c|}
\hline \multicolumn{10}{|c|}{$\begin{array}{l}\text { Dependent Variable: } \ln Y \\
K=0.01 \\
\text { Maximum Iterations: } 50\end{array}$} \\
\hline $\mathbf{K}$ & $\ln L$ & $\ln K$ & $\ln E$ & $\ln L * \ln K$ & $\ln L * \ln E$ & $\ln K * \ln E$ & $(\ln L)^{2}$ & $(\ln K)^{2}$ & $(\ln E)^{2}$ \\
\hline 0.00 & 5245 & 9989 & 1412 & 2043 & 2278 & 3814 & 3718 & 8006 & 8129 \\
\hline 0.01 & 3.52 & 6.09 & 1.24 & 0.29 & 2.32 & 2.93 & 4.08 & 5.53 & 8.95 \\
\hline 0.02 & 2.02 & 3.45 & 0.70 & 0.26 & 1.23 & 1.61 & 2.35 & 3.10 & 4.38 \\
\hline 0.03 & 1.42 & 2.29 & 0.52 & 0.24 & 0.86 & 1.12 & 1.64 & 2.06 & 2.61 \\
\hline 0.04 & 1.09 & 1.65 & 0.43 & 0.22 & 0.68 & 0.85 & 1.25 & 1.49 & 1.83 \\
\hline 0.05 & 0.88 & 1.26 & 0.37 & 0.21 & 0.57 & 0.69 & 1.00 & 1.13 & 1.40 \\
\hline 0.06 & 0.74 & 0.99 & 0.33 & 0.20 & 0.49 & 0.58 & 0.84 & 0.90 & 1.13 \\
\hline 0.07 & 0.64 & 0.81 & 0.30 & 0.19 & 0.43 & 0.51 & 0.72 & 0.73 & 0.95 \\
\hline 0.08 & 0.56 & 0.67 & 0.27 & 0.18 & 0.39 & 0.45 & 0.63 & 0.61 & 0.82 \\
\hline 0.09 & 0.51 & 0.57 & 0.25 & 0.18 & 0.36 & 0.40 & 0.56 & 0.52 & 0.72 \\
\hline
\end{tabular}

Source: Data processed by the author

The ridge regression estimates of the trans-log production specification are reported in Table 4. All the statistical indicators reveal that the ridge regression findings are statistically significant. The coefficient of determination $\left(\mathrm{R}^{2}\right)$, standard error (S.E), variance inflation factor (VIF), probability value (Prob. level), and significance level of regression equation (F-statistic), etc. report that the proposed model is reasonable. Furthermore, the main feature of the proposed framework is whether this specification is acceptable or not depends on whether the ridge regression has effectively resolved multicollinearity and similarly, whether the estimated coefficients are acceptable or not. According to Table 4, all tests of parameter estimates are efficient due to their smaller standard errors, all of which are less than 0.1 . In addition, all of the estimated coefficients support the economic theory as expected. Both the cross-influence item and square-influence item are positive, indicating that all inputs exhibit IRS. Based on the analysis, the estimated coefficients appear reasonable, and we can proceed to estimate input elasticities and substitution elasticities for the input factors considered.

Based on the model's estimates in Table 4, Equations (7) to (9) are used to calculate output elasticities for labour, capital, and energy. Calculated output elasticities are presented in Table 5. In the sample period, all the input factors showed rising output elasticities, showing a rising tendency in consumption as the economy expanded. The estimated output elasticities of all factors are characterized by elastic behaviour, with capital showing the greatest 
responsiveness to economic growth. This reveals that Pakistan's economic growth is greatly dependent on increased capital stocks and technological progress. Figure 4 also shows that the capital is more elastic, followed by labour and energy.

Table 4: Model results of the Ridge Regression estimation

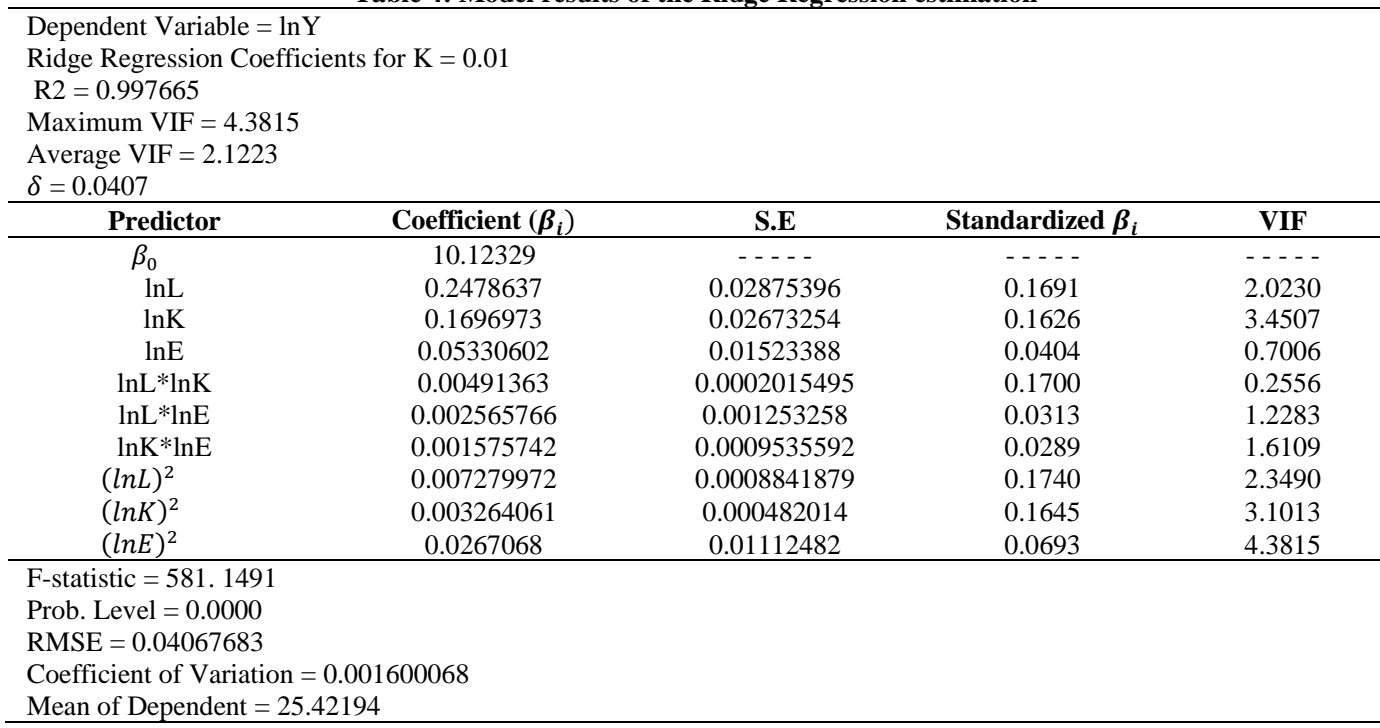

Source: Data processed by the author

Figure 4: Plot of Output Elasticity of factor inputs over the period studied.

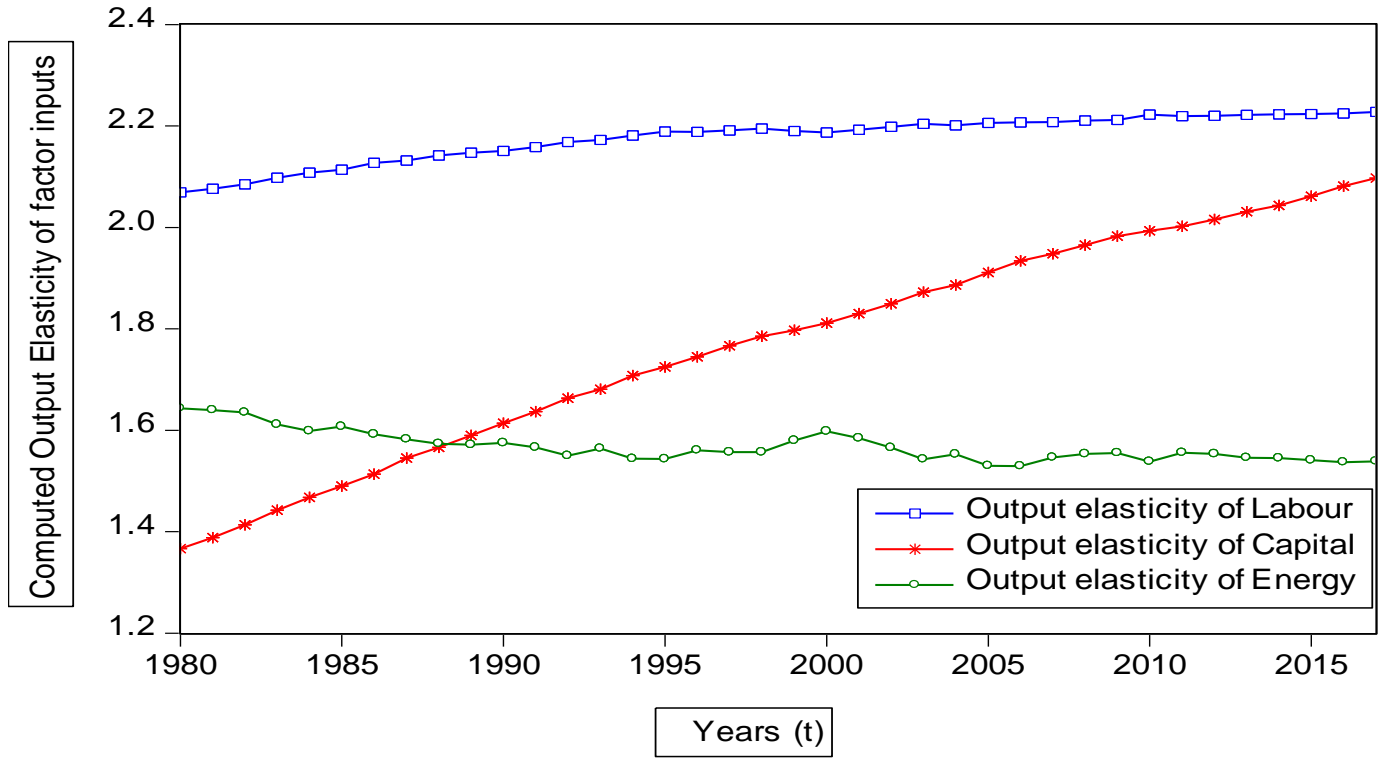

Source: Results extracted from the EViews 9.0 
Estimation of Substitution Possibilities between Hydroelectricity and Classical factor inputs for Pakistan's Economy

Table 5: Output elasticity of labour, capital and energy

\begin{tabular}{|c|c|c|c|}
\hline $\mathbf{T}$ & $\vartheta L$ & $\vartheta K$ & $\vartheta E$ \\
\hline 1980 & 2.069288 & 2.366278 & 1.643242 \\
\hline 1981 & 2.076213 & 2.388177 & 1.639419 \\
\hline 1982 & 2.085099 & 2.413749 & 1.634803 \\
\hline 1983 & 2.097575 & 2.442023 & 1.611746 \\
\hline 1984 & 2.107975 & 2.467619 & 1.598334 \\
\hline 1985 & 2.113878 & 2.489877 & 1.607190 \\
\hline 1986 & 2.127317 & 2.513222 & 1.592344 \\
\hline 1987 & 2.131799 & 2.545079 & 1.582362 \\
\hline 1988 & 2.141669 & 2.566032 & 1.572991 \\
\hline 1989 & 2.147271 & 2.589554 & 1.571713 \\
\hline 1990 & 2.150502 & 2.613657 & 1.575242 \\
\hline 1991 & 2.158584 & 2.636622 & 1.566123 \\
\hline 1992 & 2.168520 & 2.662981 & 1.549988 \\
\hline 1993 & 2.172567 & 2.681042 & 1.563978 \\
\hline 1994 & 2.181086 & 2.707650 & 1.543907 \\
\hline 1995 & 2.188852 & 2.724748 & 1.543422 \\
\hline 1996 & 2.188176 & 2.744517 & 1.560499 \\
\hline 1997 & 2.190917 & 2.766536 & 1.556946 \\
\hline 1998 & 2.194452 & 2.785254 & 1.556801 \\
\hline 1999 & 2.190255 & 2.797321 & 1.579461 \\
\hline 2000 & 2.186797 & 2.811247 & 1.597881 \\
\hline 2001 & 2.192290 & 2.829795 & 1.584460 \\
\hline 2002 & 2.198167 & 2.849337 & 1.565503 \\
\hline 2003 & 2.203841 & 2.872358 & 1.542475 \\
\hline 2004 & 2.201074 & 2.886581 & 1.552748 \\
\hline 2005 & 2.205717 & 2.911115 & 1.529947 \\
\hline 2006 & 2.207187 & 2.934193 & 1.528993 \\
\hline 2007 & 2.207927 & 2.948236 & 1.546182 \\
\hline 2008 & 2.210753 & 2.964796 & 1.553052 \\
\hline 2009 & 2.211754 & 2.982837 & 1.555031 \\
\hline 2010 & 2.222579 & 2.993477 & 1.538242 \\
\hline 2011 & 2.219600 & 2.001970 & 1.555394 \\
\hline 2012 & 2.219901 & 2.015818 & 1.553593 \\
\hline 2013 & 2.221551 & 2.031021 & 1.545864 \\
\hline 2014 & 2.222979 & 2.043070 & 1.545110 \\
\hline 2015 & 2.223680 & 2.061542 & 1.541200 \\
\hline 2016 & 2.224581 & 2.081297 & 1.537110 \\
\hline 2017 & 2.227733 & 2.097279 & 1.538857 \\
\hline Average $(\bar{X})$ & 2.176055 & 2.768892 & 1.567425 \\
\hline
\end{tabular}

Source: Data processed by the author

As per Equations (18) to (20), we have estimated the substitution elasticities for the pairs of inputs using the estimates of ridge regression and the estimates of output elasticities shown in Tables 4 and 5. In Table 6, all the pairs of substitution elasticities between the three inputs show a positive trend over time, indicating that these input factors are substitutes. Considering the existing empirical literature, the two inputs of energy and capital may be viewed either as substitutes/complements (Ma et al., 2010). Focusing on energy-capital substitutability, the empirical literature shows mixed results regarding whether they are substitutes/complements. Hudson and Jorgensen (1973), Fuss (1977), 
Berndt and Wood (1979), and Magnus (1979) and other empirical studies found Table 6: Substitution Elasticity of labour, capital and energy

\begin{tabular}{|c|c|c|c|}
\hline $\mathbf{t}$ & $\delta_{L K}$ & $\delta_{L E}$ & $\delta_{K E}$ \\
\hline 1980 & 1.01529463 & 0.78229044 & 0.95032422 \\
\hline 1981 & 1.01526496 & 0.78580186 & 0.95025946 \\
\hline 1982 & 1.01523051 & 0.79001478 & 0.95017979 \\
\hline 1983 & 1.01519278 & 0.79995817 & 0.94967988 \\
\hline 1984 & 1.01515872 & 0.80596316 & 0.94939019 \\
\hline 1985 & 1.01512903 & 0.80537153 & 0.94961773 \\
\hline 1986 & 1.01509848 & 0.81197337 & 0.94928983 \\
\hline 1987 & 1.01505610 & 0.81506776 & 0.94907994 \\
\hline 1988 & 1.01502880 & 0.81902917 & 0.94887189 \\
\hline 1989 & 1.01499792 & 0.82042602 & 0.94886155 \\
\hline 1990 & 1.01496625 & 0.82043169 & 0.94896858 \\
\hline 1991 & 1.01493651 & 0.82368967 & 0.94876601 \\
\hline 1992 & 1.01490257 & 0.82825815 & 0.94838841 \\
\hline 1993 & 1.01487922 & 0.82671235 & 0.94875180 \\
\hline 1994 & 1.01484513 & 0.83141449 & 0.94827364 \\
\hline 1995 & 1.01482345 & 0.83280209 & 0.94827598 \\
\hline 1996 & 1.01479785 & 0.83009429 & 0.94872032 \\
\hline 1997 & 1.01476967 & 0.83112212 & 0.94865083 \\
\hline 1998 & 1.01474587 & 0.83175231 & 0.94866307 \\
\hline 1999 & 1.01473017 & 0.82741768 & 0.94922921 \\
\hline 2000 & 1.01471217 & 0.82359288 & 0.94968133 \\
\hline 2001 & 1.01468889 & 0.82696292 & 0.94937716 \\
\hline 2002 & 1.01466445 & 0.83106371 & 0.94893236 \\
\hline 2003 & 1.01463568 & 0.83539580 & 0.94837593 \\
\hline 2004 & 1.01461759 & 0.83347256 & 0.94864662 \\
\hline 2005 & 1.01458705 & 0.83740666 & 0.94808736 \\
\hline 2006 & 1.01455826 & 0.83776018 & 0.94808159 \\
\hline 2007 & 1.01454079 & 0.83553195 & 0.94853216 \\
\hline 2008 & 1.01452036 & 0.83501811 & 0.94871846 \\
\hline 2009 & 1.01449804 & 0.83489882 & 0.94878266 \\
\hline 2010 & 1.01448552 & 0.83888749 & 0.94836723 \\
\hline 2011 & 1.01447485 & 0.83611089 & 0.94880725 \\
\hline 2012 & 1.01445779 & 0.83640897 & 0.94877342 \\
\hline 2013 & 1.01443919 & 0.83772097 & 0.94859118 \\
\hline 2014 & 1.01442449 & 0.83804214 & 0.94858178 \\
\hline 2015 & 1.01440192 & 0.83866688 & 0.94849731 \\
\hline 2016 & 1.01437788 & 0.83933599 & 0.94840866 \\
\hline 2017 & 1.01435862 & 0.83958227 & 0.94846600 \\
\hline Average $(\bar{X})$ & 1.01477085 & 0.82514343 & 0.94889344 \\
\hline
\end{tabular}

Source: Data processed by the author

energy vs. capital as complements; however, other empirical studies have established energy and capital as substitutes (Griffin and Gregory, 1976; Pindyck, 1979; Smyth et al., 2011; Khalid et al., 2021). In our analysis, we established that the substitution elasticity between energy vs. capital to be positive and close to unity (0.94) during the sampling period studied, wherein the result being consistent with the estimates of Vega-Cervera and Medina (2000) for Portugal, Christopoulos and Tsionas (2002) for Greece, Cho et al (2004) for South Korea, Smyth et al (2011) for China, Presley et al (2013) for Liberia, and Lin and Liu (2017) for China, etc. This is a slightly higher value than that concluded by the 
majority of studies on the Chinese economy, with computed values in the range 0.6-0.8 (Griffin and Gregory, 1976; Ma et al., 2008, 2009); however, it is considerably lower than Zheng and Liu2 (2004) estimate of greater than 2.50. This finding suggests that the elimination of energy subsidies and price ceilings to reflect actual energy costs in Pakistan will significantly reduce energy usage and encourage capital-intensive industry. As suggested by (Ma et al., 2008; Smyth et al., 2011; Khalid et al., 2021), the possible substitution type involves manual operation, semi-mechanical process, and some kind of production system. Based on the substitutability between labour and energy, we see that this elasticity estimate is gradually rising from 0.78 to 0.83 , which suggests Pakistan should invest more in skilled employment generation to conserve energy in the future. There are studies that report lower substitution elasticity between labour vs. energy in China than between capital vs. energy (Zheng and Liu, 2004; Fan et al., 2007; Ma et al., 2008, 2009). In industries, heavy machines have been introduced in order to increase productivity. This allows the pair of energy and labour inputs to be easily substituted. Pakistan's demographic advantage has been declining due to an increase in labour costs, brain drain, less attractive job opportunities, and aging of the population. In Pakistan, these crucial issues lead us to accept that the substitution elasticity between labour vs. energy is lower than the substitution elasticity between capital vs. energy. Finally, the substitution elasticity between labour and capital inputs is slightly above unity (1.01), and this elasticity estimate has almost remained constant over time. This highest estimated elasticity coefficient indicates a possibility to substitute labour inputs for capital inputs, which supports the findings of Smyth et al (2011) and Khalid et al (2021). The substitution elasticities are shown in Figure 5.

Figure-5: The substitution elasticity between labour, capital and energy.

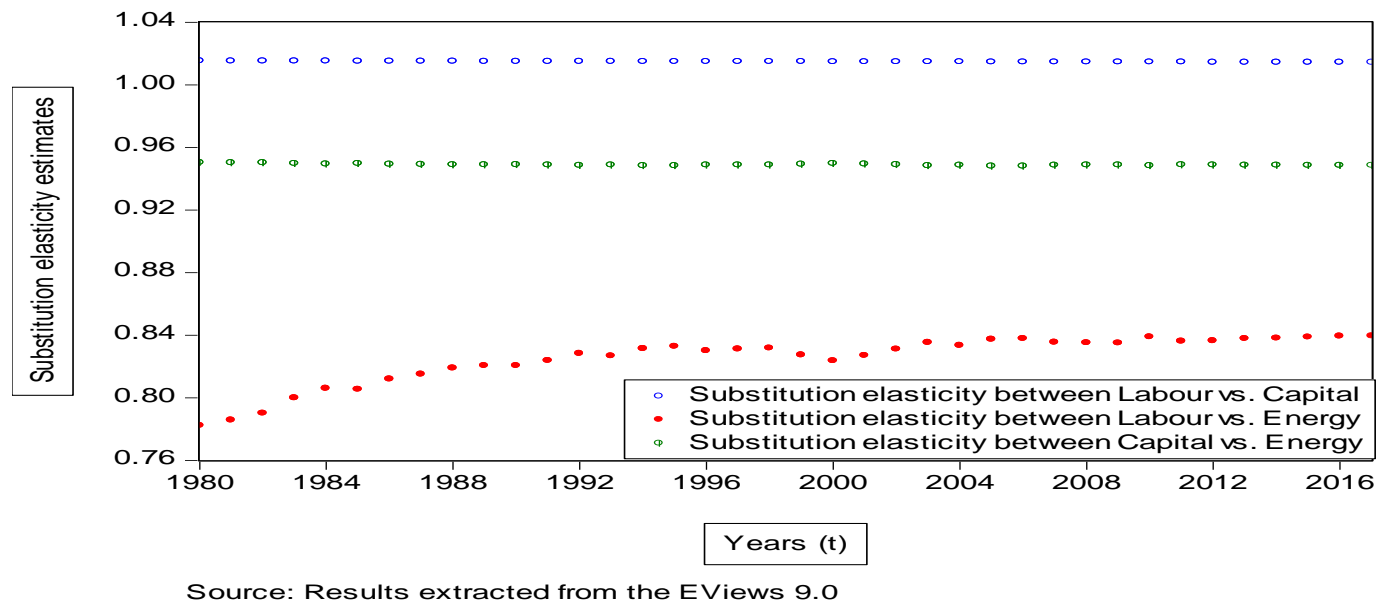


In the current study, we also calculated the relative differences in technological change for all selected input pairs spanning from 1980-2017. We used the aggregate trans-log production specification of Pakistan's economy along with the output elasticities and estimated parameters from the proposed model given in Equation (6). To perform the required calculations, we have used Equation (29), which has also been used by Smyth et al (2010, 2012), Xie and Hawkes (2015), Lin and Atsagli (2017) and Khalid et al (2021).

$$
D_{i j}=\frac{\beta_{i}}{\vartheta_{i}}-\frac{\beta_{j}}{\vartheta_{j}}
$$

Where $D_{i j}$ represents the difference between technological progresses of inputs $i$ and $j, \beta_{i}$ and $\beta_{j}$ show the parameter estimates, and $\vartheta_{i}$ and $\vartheta_{j}$ show the output state of technological progress of inputs $i$ and $j$. If $D_{i j}>0$, indicating that the state of technological change for $i$ is faster than $j$; if $D_{i j}<0$, indicating that the technological change for $i$ is slower than $j$; and if $D_{i j}=0$, indicating that the state of technological change for the two factors is growing at the same pace. The calculated values for technological progress are reported in Table 7.

Table 7: Difference in technological progress between the pairs of labour, capital and energy

\begin{tabular}{|c|c|c|c|}
\hline $\mathbf{T}$ & $D_{\text {Labour vs.Capital }}$ & $D_{\text {Labour vs.Energy }}$ & $D_{\text {Capital vs.Energy }}$ \\
\hline 1980 & 0.06741347 & 0.05713340 & -0.01028007 \\
\hline 1981 & 0.06716840 & 0.05680349 & -0.01036492 \\
\hline 1982 & 0.06685328 & 0.05638681 & -0.01046647 \\
\hline 1983 & 0.06640612 & 0.05555091 & -0.01085522 \\
\hline 1984 & 0.06604011 & 0.05494285 & -0.01109726 \\
\hline 1985 & 0.06584358 & 0.05485812 & -0.01098546 \\
\hline 1986 & 0.06536689 & 0.05411838 & -0.01124851 \\
\hline 1987 & 0.06523875 & 0.05379122 & -0.01144752 \\
\hline 1988 & 0.06489872 & 0.05327357 & -0.01162515 \\
\hline 1989 & 0.06472126 & 0.05304669 & -0.01167457 \\
\hline 1990 & 0.06463203 & 0.05298593 & -0.01164610 \\
\hline 1991 & 0.06436525 & 0.05254219 & -0.01182306 \\
\hline 1992 & 0.06403789 & 0.05191471 & -0.01212317 \\
\hline 1993 & 0.06391420 & 0.05200264 & -0.01191157 \\
\hline 1994 & 0.06364183 & 0.05136280 & -0.01227903 \\
\hline 1995 & 0.06338702 & 0.05107952 & -0.01230749 \\
\hline 1996 & 0.06343421 & 0.05138982 & -0.01204439 \\
\hline 1997 & 0.06336346 & 0.05123407 & -0.01212939 \\
\hline 1998 & 0.06326108 & 0.05110732 & -0.01215375 \\
\hline 1999 & 0.06342283 & 0.05162728 & -0.01179555 \\
\hline 2000 & 0.06356115 & 0.05204421 & -0.01151694 \\
\hline 2001 & 0.06338900 & 0.05163631 & -0.01175269 \\
\hline 2002 & 0.06320545 & 0.05112134 & -0.01208411 \\
\hline 2003 & 0.06303401 & 0.05053802 & -0.01249599 \\
\hline 2004 & 0.06314685 & 0.05080776 & -0.01233909 \\
\hline 2005 & 0.06301330 & 0.05025827 & -0.01275502 \\
\hline 2006 & 0.06298864 & 0.05019073 & -0.01279791 \\
\hline 2007 & 0.06297896 & 0.05045879 & -0.01252017 \\
\hline 2008 & 0.06289992 & 0.05047648 & -0.01242343 \\
\hline
\end{tabular}




$\begin{array}{llll}2009 & 0.06288576 & 0.05047498 & -0.01241078 \\ 2010 & 0.06252542 & 0.04981903 & -0.01270638 \\ 2011 & 0.06263712 & 0.05021077 & -0.01242636 \\ 2012 & 0.06264239 & 0.05017031 & -0.01247208 \\ 2013 & 0.06260294 & 0.04998375 & -0.01261919 \\ 2014 & 0.06256755 & 0.04992208 & -0.01264546 \\ 2015 & 0.06256424 & 0.04983177 & -0.01273247 \\ 2016 & 0.06255548 & 0.04973122 & -0.01282427 \\ 2017 & 0.06246574 & 0.04965353 & -0.01281221\end{array}$

Source: Data processed by the author

According to Figure 6, there are differences in the relative technical change for the three factors; however, the difference is small, which suggests a convergence in technological change over time. This indicates that the inputs are being technologically changed efficiently. Other than capital versus energy, which indicates a negative relative difference over the period, all other resource pairs indicate a positive change in technologies. In other words, technological change in labour is faster than in capital and energy. On the other hand, capital has experienced a lower level of technological change than energy. Despite the fact that labour is progressing faster than capital and energy, hydroelectricity plays an essential role in Pakistan's energy mix by providing clean energy.

Figure-6: Difference among technical progresses of different factor inpts.

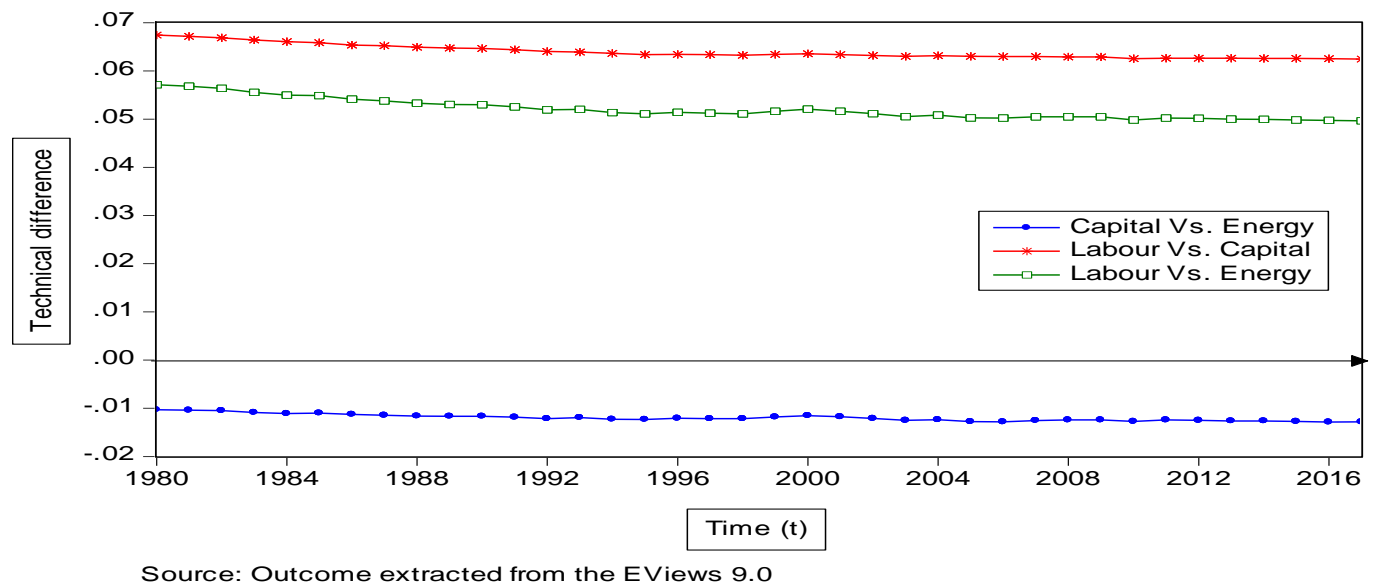

\section{Conclusion and Policy Recommendations}

Pakistan faces the question of which factor input can replace energy and how this factor substitution impacts the country's economic growth (Khalid et al., 2021). The trans-log production specification was employed in the context of time-series data between 1980 and 2017 to examine technological progress, output elasticities, and substitution elasticity between labour, capital, and energy. We used ridge regression and ridge trace plots as estimation techniques after we 
discovered significant multicollinearity in our dataset. In the present study, we found the following major empirical findings:

1. The results show a positive significant association between labour vs. capital, labour vs. energy, and capital vs. energy to Pakistan's economy; however, all factor inputs are substitutes.

2. The findings demonstrate convergence in the whole pair of technological advancement among the factors considered, a sign that labour vs. capital are significant substitutes for energy. It provides the opportunity to provide clean energy in place of greenhouse gas-emitting petroleum products and employment generation. By reducing petroleum imports, this policy action will reduce Pakistan's BOP deficit, which will result in energy conservation and less vulnerability to global oil price shocks.

3. The findings indicate that capital and energy can be substituted for each other, meaning that when consumers will pay the actual cost of energy by removing energy subsidies, they will tend to discourage inefficient energy consumption in favor of capital formation. As a result, Pakistan's capital stock demonstrates greater substitutability to energy as compared to labour, evidence that Pakistan's capital has higher investment incentives. In this case, manual operations, semi-mechanical operation, and other production processes may be used. This also means that the reduction of energy use is equivalent to an increase in capital stock formation (Liao et al., 2007; Ma et al., 2009; Khalid and Jalil, 2019).

4. The findings of the study show that labour and energy are significant substitutes, which means that Pakistan has yet another opportunity to hire an efficient and skilled labor force to reduce energy use in the future, and thereby reduce unemployment rates.

5. The empirical results showed a relatively strong convergence in technological change among all the input factors; as a consequence, extending the technological progress of any one factor would make it a dominant factor over the other during the period.

According to the findings of the study, Pakistan's future energy policy has a significant chance of responding to the international outcry to mitigate $\mathrm{CO}_{2}$ emissions alongside economic growth and an improved energy market, as specified in Pakistan's 2025 policy document, "one nation one vision". Pakistan has decided to increase access to power to its people from 67 percent to 90 percent by introducing a diversified energy-mix, reducing environmental degradation, and boosting economic growth to make Pakistan one of the top 25 countries in the world. Considering these targets, a few recommendations are 
suggested in the study:

Due to the fact that all input pairs are substitutable and because of the differences in their technological progress, these input pairs are efficient over time. Accordingly, Pakistan's government should focus on a favored input to improve its policy to promote alternative energy sources and a diverse energy supply mix along with sustainable economic growth. As labour and capital are substitutes, labour's technological progress is higher than that of capital. Therefore, the Pakistani government should focus on increased economic growth by encouraging skilled employment creation. According to the results, capital is also a substitute for energy; therefore, Pakistani government should focus on promoting capital intensiveness and technological advancement as well as enhancing energy conservation. It is recommended that the government of Pakistan invest in hydropower by providing incentives such as taxes, subsidies, and power infrastructure development in order to discourage environmentally harmful petroleum products. This will encourage the government to support a diversified energy-mix to achieve environmental sustainability and energy conservation.

Despite the importance of this research, there are still some limitations to the study that need to be addressed. It is important to keep in mind that the specification of the proposed trans-log production model and the loss of efficiency that resulted from the inclusion of a large number of parameters should not be considered final. That's because the proposed model framework has to account for some degree of bias. As a result of these limitations, the authors were unable to incorporate other most relevant variables into the model. Thus, overcoming these limitations might be an interesting area of future research and model improvement. 


\section{References}

Adeyemo, O. O., Mabugu, R., \& Hassan, R. H. (2007). Inter-fuel substitution: The case of the Nigerian industrial sector. Journal of Energy in Southern Africa, 18(1), 39-50.

Aghion, P., \& Howitt, P. (2009). The Economics of Growth. MIT Press.

Apostolakis, B. E. (1990). Energy-capital substitutability/complementarity: The dichotomy. Energy Economics, 1, 48-58.

Asteriou, D., \& Hall, S. (2011). Applied Econometrics (Second Edition). Basingstoke: Palgrave Macmillan.

Aziz, A. A. (2007). The Potential of Energy Substitution in the Industrial Sector. Department of Economics, Faculty of Management and Economics, Terengganu, Malaysia, 1-26.

Barney, F., \& Franzi, P. (2002). The future of energy From Future Dilemmas: Options to 2050 for Australia's population, technology, resources and environment. CSIRO Sustainable Ecosystems, 157-189.

Battese, G. E., \& Malik, S. J. (1988). Estimation of elasticities of substitution for CES and VES production functions using firm level data for foodprocessing industries in Pakistan. The Pakistan Development Review, 27(1), 59-71.

Bayar, Y., \& Ozel, H. A. (2014). Electricity consumption and economic growth in emerging economies. Journal of Knowledge Management, Economics and Information Technology, 4(2), 1-18.

Behrman, J. R. (1972). Sectoral elasticities of substitution between capital and labour in development economy: Time series analysis in the case of postwar Chile. Econometrica, 40(2), 311-326.

Berndt, E. R., \& Wood, D. O. (1975). Technology, prices, and the derived demand for energy. The Review of Economics and Statistics, 57(3), 259268.

Chishti, S., \& Mahmood, F. (1991). The energy demand in the industrial sector of Pakistan. The Pakistan Development Review, 30(1), 83-88.

Cho, W. G., Nam, K., \& Pagan, J. A. (2004). Economic growth and interfactor/inter-fuel substitution in Korea. Energy Economics, 26(1), 31-50. 
Christensen, L. R., Jorgenson, D. W., \& Lau, L. J. (1973). Transcendental logarithmic production frontiers. The Review of Economics and Statistics, 55(1), 28-45.

Christopoulos, D. K., \& Tsionas, E. G. (2002). Allocative inefficiency and the capital-energy controversy. Energy Economics, 24(4), 305-318.

Fan, Y., Liou, H., \& Wei, Y. (2007). Can market-oriented economic reforms contribute to energy efficiency improvement? Evidence from China. Energy Policy, 35(4), 2287-2295.

Fuss, M. A. (1977). The demand for energy in Canadian manufacturing: An example of the estimation of production structures with many inputs. Journal of Economics, 5(1), 89-116.

Goldar, B. (2012). Input substitution and technical change in Indian manufacturing, 1973-2007. The Journal of Industrial Statistics, 1(2), 169181.

Government of Pakistan. (2013). Pakistan vision 2025: One nation-one vision. Planning Commission, Ministry of Planning, Development \& Reform, Islamabad.

Government of Pakistan. (2015). Economic Survey (2014-2015). Ministry of Finance: Islamabad.

Government of Pakistan. (2020). Economic Survey (2019-2020). Ministry of Finance: Islamabad.

Government of Pakistan. (2021). Economic Survey (2020-2021). Ministry of Finance: Islamabad.

Griffen, J. M., \& Gregory, P. R. (1976). An Inter-country Trans-log model of energy substitution responses. The American Economic Review, 66(5), 845-857.

Gujarati, D. (2004). Basic Econometrics (4 ${ }^{\text {th }}$ Edition). McGraw-Hill companies.

Halvorsen, R. (1977). Energy substitution in U. S. manufacturing. Review of Economics and Statistics, 59(4), 381-388.

Hamilton, J. D. (2009). Causes and consequences of the oil shock of 2007-08. Brookings Papers on Economic Activity, 1, 215-261.

Hoerl, A. E., \& Kennard, R. W. (1970). Ridge regression: Biased estimation for nonorthogonal problems. Technometrics, 12(1), 55-67. 
Hou, Q. (2009). The relationship between energy consumption growths and economic growth in China. International Journal of Economics and Finance, 1(2), 232-237.

Hudson, E. A., \& Jorgenson, D. W. (1973). U. S. energy policy and economic growth, 1975-2000. Bell Journal of Economics, 5(2), 461-514.

Humphrey, D. B., \& Moroney, J. R. (1975). Substitution among capital, labor and natural resources products in American manufacturing. Journal of Political Economy, 83(1), 57-82.

Kamran, M., Fazal, M. R., \& Mudassar, M. (2020). Towards empowerment of the renewable energy sector in Pakistan for sustainable energy evolution: SWOT analysis. Renewable Energy, 146, 543-558.

Ketteni, E., Mamuneas, T., \& Pashardes, P. (2013). ICT and energy-use: Patterns of substitutability and complementarity in production. Cyprus Economic Policy Review, 7(1), 63-86.

Khalid, W. \& Jalil, A. (2019). An econometric analysis of inter-fuel substitution in energy sector of Pakistan. Environmental Science and Pollution Research, 26(17), 17021-17031.

Khalid, W., Özdeşer, H., \& Jalil, A. (2021). An empirical analysis of Inter-factor and Inter-fuel substitution in the energy sector of Pakistan. Renewable Energy, 177, 953-966.

Khan, A. H. (1989). The two-level CES production function for the manufacturing sector of Pakistan. The Pakistan Development Review, 28(1), 1-12.

Khan, A. H., \& Rafiq, M. (1993). Substitution among labour, capital, imported raw materials, and bank credit in Pakistan's manufacturing. The Pakistan Development Review, 32(4), 1259-1266.

Khan, A., Mehmood, B., \& Ali, S. (2015). Is Pakistan's banking sector production function Cobb-Douglas? estimates of the elasticity of substitution. Science International, 27(3), 2775-2778.

Khan, M., \& Burki, A. A. (2000). Estimating allocative efficiency and elasticities of substitution in large-scale manufacturing sector of Pakistan. Pakistan Journal of Applied Economics, 16(1), 49-63. 
Khilji, N. M. (1982). Growth prospects of a developing economy: A macroeconomic study of Pakistan. Doctoral Dissertation, McMaster University, Canada.

Koetse, M. J., Groot, H. L. F., \& Florax, R. J. G. M. (2008). Capital-energy substitution and shifts in factor demand: A meta-analysis. Energy Economics, 30(5), 2236-2251.

Krishnapillai, S., \& Thompson, H. (2012). Cross section trans-log production and elasticity of substitution in U.S. manufacturing industry. International Journal of Energy Economics and Policy, 2(2), 50-54.

Liao, H., Fan, Y., \& Wei, Y. (2007). What induced China's energy intensity to fluctuate: 1997-2006? Energy Policy, 35(9), 4640-4649.

Lin, B., \& Ahmad, I. (2016). Technical change, inter-factor and inter-fuel substitution possibilities in Pakistan: A trans-log production function approach. Journal of Cleaner Production, 126, 537-549.

Lin, B., \& Atsagli, P. (2017). Energy consumption, inter-fuel substitution and economic growth in Nigeria. Energy, 120, 675-685.

Lin, B., \& Fei, R. (2015). Analyzing inter-factor substitution and technical progress in the Chinese agriculture sector. European Journal of Agronomy, 66, 54-61.

Lin, B., \& Liu, K. (2017). Energy substitution effect on China's heavy industry: Perspective of a trans-log production function and ridge regression. Sustainability, 9(11), 1-15.

Lin, B., \& Wessseh, P. K. J. (2013). Estimates of inter-fuel substitution possibilities in Chinese chemical industry. Energy Economics, 40(C), 560568.

Ma, H., Oxley, L., \& Gibson, J. (2009). Substitution possibilities and determinants of energy intensity for China. Energy Policy, 37(5), 17931804.

Ma, H., Oxley, L., Gibson, J., \& Kim, B. (2008). China's energy economy: Technical change, factor demand and inter-factor/inter-fuel substitution. Energy Economics, 30(5), 2167-2183.

Ma, H., Oxley, L., Gibson, J., \& Kim, B. (2009). Modeling China's energy consumption behavior and changes in energy intensity. Environmental Modelling and Software, 24(11), 1293-1301. 
Magnus, J. R. (1979). Substitution between energy and non-energy inputs in the Netherlands 1950 - 1976. International Economic Review, 20(2), 465484.

Mahmood, Z. (1989). Derived demand for factors in the large scale manufacturing sector of Pakistan. The Pakistan Development Review, 28 (4), 731-742.

Mahmud, S. F. (2000). The energy demand in the manufacturing sector of Pakistan: Some further results. Energy Economics, 22(6), 641-648.

Morrison, C. (1993). Energy and capital: Further exploration of E-K interactions and economic performance. The Energy Journal, 14(1), 217-243.

Naqvi, S. N. H., Khan, A. H., Khilji, N. M., \& Ahmed, A. M. (1983). The P.I.D.E. Macro-Econometric Model of Pakistan's Economy. Pakistan Institute of Development of Economics, Islamabad.

Onuonga, S. M., Etyang, M., \& Mwabu, G. (2011). The demand for energy in the Kenyan manufacturing sector. The Journal of Energy and Development, 34(2), 265-276.

Pavelescu, F. M. (2011). Some aspects of the translog production function estimation. Romanian Journal of Economics, 32(1), 41.

Pindyck, R. S. (1979). Inter-fuel substitution and the industrial demand for energy: An international comparison. The Review of Economics and Statistics, 61(2), 169-179.

Presley, K. W., Lin, B., \& Appiah, M. O. (2013). Delving into Liberia's energy economy: Technical change, inter-factor and inter-fuel substitution. Renewable and Sustainable Energy Reviews, 24 (C), 122-130.

State Bank of Pakistan (2010). Handbook of Statistics on Pakistan Economy.

Shakeel, S. R., Takala, J., \& Shakeel, W. (2016). Renewable energy sources in power generation in Pakistan. Renewable and Sustainable Energy Review, 64(C), 421-434.

Smyth, R., Narayan, P. K., \& Shi, H. (2010). Inter-fuel substitution in the Chinese iron and steel sector. Monash University Economics Discussion Paper, 22/10, 1-33.

Smyth, R., Narayan, P. K., \& Shi, H. (2012). Inter-fuel substitution in the Chinese iron and steel sector. International Journal of Production Economics, 139(2), 525-532. 
Smyth, R., Narayan, P. K., Shi, H. (2011). Substitution between energy and classical factor inputs in the Chinese steel sector. Applied Energy, 88(1), 361-367.

Stern, D. I. (2010). The role of energy in economic growth. Centre for Climate Economics and Policy, Crawford School of Economics and Government Working Paper 3/10,1-50.

Thompson, P., \& Taylor, G. T. (1995). The capital energy substitutability debate: A new look. The Review of Economics and Statistics, 77(3), 565-569.

Vega-Cervera, J. A., \& Medina, J. (2000). Energy as a productive unit: The underlying technology for Portugal and Spain. Energy, 25(8), 757-775.

Wang, X., \& Lin, B. (2017). Factor and fuel substitution in China's iron \& steel industry: Evidence and policy implications. Journal of Cleaner Production, 141(C), 751-759.

Wesseh Jr., P. K., \& Lin, B. (2016). Modeling environmental policy with and without abatement substitution: A tradeoff between economics and environment? Applied Energy, 167(C), 34-43.

Xie, C., Hawkes, A. D. (2015). Estimation of inter-fuel substitution possibilities in China's transport industry using ridge regression. Energy, 88(C), 260267.

Zahid, S. N., Akbar, M., \& Jaffry, S. A. (2002). Technical change, efficiency, and capital-labor substitution in Pakistan's large-scale manufacturing sector. The Pakistan Development Review, 31(2), 165-188.

Zheng, Z. N., \& Liu, De, S. (2004). China's trans-log production function using capital, energy and labor as input. Systems Engineering - Theory \& Practice, 24(5), 51-54. 